\title{
Floral biology of Scaphochlamys (Zingiberaceae) focusing on Bornean taxa
}

\author{
Im-Hin Ooi ${ }^{1,2}$, Sin-Yeng Wong ${ }^{1,3,4}$ (iD \\ ${ }^{1}$ Faculty of Resource Science and Technology, Universiti Malaysia Sarawak, 94300, Kota Samarahan, Sarawak, \\ Malaysia \\ ${ }^{2}$ Penang Botanic Gardens Department, Kompleks Pentadbiran, Bangunan Pavilion, Jalan Kebun Bunga, 10350, Pulau \\ Pinang, Malaysia \\ ${ }^{3}$ Research Associate, Harvard University Herbaria, 22 Divinity Avenue, Cambridge, MA, 02138, United States \\ ${ }^{4}$ Ludwig-Maximilians-Universität München, Department Biologie I, Systematische Botanik und Mykologie, Menzinger \\ Straße 67, 80638, München, Germany
}

\begin{abstract}
An overview of the floral biology including floral odour analyses of twenty-two Bornean Scaphochlamys taxa and three ex Bornean Scaphochlamys taxa was undertaken. All Scaphochlamys species investigated bloom diurnally. Pollen is released gradually, either simultaneously with stigma secretion or later (mostly within one hour). Flowers of most Scaphochlamys species were found to emit a mild odour but a few are odourless. Stigmas and anther spurs (where present) differ among the taxa investigated. Natural fruit set percentages of all species investigated were very low, up to $14.29 \%$. Scaphochlamys species are facultatively xenogamic as the pollen/ovule ratios ( $\mathrm{P} / \mathrm{O}$ ratios) were high. Analysis of floral odour revealed 102 identifiable floral volatile organic compounds (VOCs), representing $31.8 \%$ of the compounds found. The volatile fraction was characterized by the aliphatics class $(21.5 \%)$, monoterpenes (3.4\%), irregular terpenes $(0.3 \%)$ and benzenoids and phenyl propanoids $(0.6 \%)$. Two pollinator guilds were found: halictid bees and Amegilla bees.
\end{abstract}

Submitted: March 29, 2019

Revised: July 9, 2019

Accepted: August 13, 2019

Keywords:

Amegilla bees, floral odour, halictid bees, pollen/ovule ratio, pollination shift

\section{Background}

Zingiberaceae are the largest family in the order Zingiberales comprising 56 to 62 genera and over 1,370 species (Stevens 2001 onwards; de Boer et al. 2018). The family has a pan-tropical distribution, with its centre of diversity in the Malesian biogeographic region (Kress et al. 2002; Larsen 2005). In Borneo, the gingers display great diversity and are separated into 23 genera with nearly 270 described taxa (Lamb et al. 2013; Ooi et al. 2017; de Boer et al. 2018).

Scaphochlamys Baker is a genus of 54 species in the Kaempferia Clade (sensu Kress et al. 2002)

\section{Correspondence}

Sin-Yeng Wong, Faculty of Resource Science and Technology, Universiti Malaysia, Sarawak Kota, Samarahan 94300,

Malaysia.

E-mail: sywong@unimas.my occurring from southern Thailand through Peninsular Malaysia and Sumatera, to northern Borneo (Ooi et al. 2017). Borneocola Y.Y. Sam and Myxochlamys A. Takano \& Nagam. together are sister to the remainder of Scaphochlamys. However, recognition of these as genera renders Scaphochlamys impossible to define morphologically. The clade is sister to Distichochlamys M.F. Newman (Takano \& Nagamasu 2007; Sam et al. 2016). Scaphochlamys is distinguished from Myxochlamys and Distichochlamys by the following combination of characters: petiole base pulvinate (Borneo only), spiral floral bract arrangement, flowering acroscopic, first bracteole 2-keeled and arising opposite to the bract, bracteole split to the base and anthers with free basal spurs (Searle 2010). Twenty-four Scaphochlamys species are currently recognized in Borneo, all of them endemic. The Bornean species have been classified into six informal groups based on 